\title{
The Patient Management and Professionalism Scale to Assess Dental Students' Behavior in Clinic
}

\begin{abstract}
Vidya Ramaswamy
Abstract: The Ten Item Personality Inventory (TIPI) is a widely used instrument based on a personality framework measuring five dimensions: Extraversion, Agreeableness, Conscientiousness, Emotional Stability, and Openness to Experiences. The aim of this study was to establish a scale to assess dental students' professionalism by adding to the TIPI's five dimensions a set of descriptors that define professional behavior in dental students. The resulting Patient Management and Professionalism Scale (PMPS) was then tested with a cohort of graduating students at the University of Michigan School of Dentistry. To develop the scale, one clinic director and a patient care coordinator from four clinics wrote descriptive statements for each of the five dimensions based on their observations of dental students in the context of their clinical experiences. These descriptors were compiled into a single scale. The PMPS demonstrated good scale reliability and interrater agreement and correlated significantly with students' patient management grade scores and cumulative GPA at the end of their fourth year. Exploratory factor analysis showed the presence of a single factor (professionalism) with all five dimensions loading highly on this factor, accounting for $66 \%$ of variance in scores. While a useful standardized measure to assess professionalism in dental students, the PMPS also has a flexible format that makes it easy for other schools to use.
\end{abstract}

Vidya Ramaswamy, PhD, is Associate Director of Curriculum and Program Evaluation, University of Michigan School of Dentistry. Direct correspondence to Dr. Vidya Ramaswamy, School of Dentistry, University of Michigan, Ann Arbor, MI 48109-1078; 734-647-4218; ramaswav@umich.edu.

Keywords: dental education, dental students, professionalism, assessment, personality, TIPI

Submitted for publication 3/23/18; accepted 6/29/18

doi: 10.21815/JDE.019.012

A ssessment of professionalism is important in dental education: at one dental school, dental faculty members identified professionalism and preparedness as highest in importance for dental students' overall success. ${ }^{1}$ Indeed, low ratings on professionalism among medical students were found to be more critical than low ratings on knowledge. ${ }^{2}$ This difference is because, in the assessment of clinical performance, non-cognitive indicators are more critical than academic performance indicators. ${ }^{1}$ As dental students pass through the curriculum, clinical interactions with patients become more important, ${ }^{3}$ and personality traits take on increasing meaning. Although most clinical educators agree that professionalism is important to assess as part of overall clinical performance, it is difficult to establish what constitutes professionalism because its definition is complex, even confusing and ambiguous. ${ }^{4-6}$ Furthermore, a review of 74 instruments from 84 studies found that only a limited number of instruments were methodologically sound in their assessment of professionalism. ${ }^{7}$ That review reported that the three best measures came from nursing and psychology. A definition of professionalism can include individual, interpersonal, or societal dimensions. ${ }^{6}$ Indeed, a literature review of professionalism found 90 separate elements. ${ }^{8}$ Given the complexity of the construct, clarification of what constitutes professionalism would be of value for dental education. ${ }^{9}$

Understanding and clarifying personality traits linked to professionalism may help us better assess it. It may be useful to assess these traits even prior to admission to dental school, ${ }^{6}$ as they predict long-term success and future performance in work settings as well. ${ }^{10}$ Multiple non-cognitive traits have been associated with professionalism in health professions education. In an open-ended survey of non-cognitive factors that contribute to students' success, dental faculty members identified communication/interpersonal skills (good communication, empathy, good listener), approach to learning (preparedness, willing to learn, motivation to learn and not just to complete a procedure), and perseverance (grit). ${ }^{1}$ Another noncognitive trait, empathy, has been found to be an important component of overall competence for medical students. ${ }^{11}$ Duty, responsibility, and trustworthiness 
were identified as non-cognitive traits of significance in a survey of graduating medical students, faculty, students, and other health professionals. ${ }^{5}$ Emotional intelligence has also been shown to be positively correlated with dental students' professionalism. ${ }^{12}$ Many schools do attempt to assess these types of traits: $55 \%$ of respondents to a survey of 135 medical schools reported that behaviors such as honesty, professional behavior, and dedication to learning were assessed at their school, and those respondents who said their schools lacked clear criteria for assessment of non-cognitive behaviors reported that this lack of assessment has led to cheating. ${ }^{2}$ It is the moral and social responsibility of schools to address professionalism as it has implications for upholding standards of care. ${ }^{2,6}$

The assessment of non-cognitive traits related to professionalism is not an easy task. One challenge is that non-cognitive traits cannot be assessed objectively, so human judgment is necessary. A second challenge is the administrative burden associated with such assessments. ${ }^{2} \mathrm{~A}$ third challenge is the need for multiple raters.

Even with these challenges, a validated scale is available to assist with assessment of professionalism: the Ten Item Personality Inventory (TIPI). This scale is brief, can be used by multiple raters, and is easily implemented. The TIPI is based on the Five
Factor Model and the Big 5 trait theory universal approach to measuring personalities that has been found to be stable across cultures and diverse ethnic groups and over time and daily events. ${ }^{13-16}$ Based on descriptors provided by Goldberg's Big-Five MiniMarkers, BFI, and John and Srivastava's Adjective Checklist Big-Five Markers, Gosling et al. developed the TIPI as a ten-item measure of the big five dimensions of personality (Table 1). ${ }^{17,18}$ The ten items are divided into five scales, each of which consists of two contrasting items used to assess each of the five personality domains: Extraversion, Agreeableness, Conscientiousness, Emotional Stability, and Openness to Experience. Each item is rated on a seven-point Likert scale from $1=$ strongly disagree to $7=$ strongly agree. The five dimensions are as follows: Extraversion is the quantity and intensity of interpersonal interaction; Agreeableness is the quality of one's interpersonal interactions along a continuum from compassion to antagonism; Conscientiousness is the amount of persistence, organization, and motivation in goal-directed behaviors; Emotional Stability is the absence of neurotic behavior, reflecting a calm, relaxed approach to situations, events, or people and an emotionally controlled response to changes in the work environment; and Openness to Experience is proactively seeking and appreciating new experiences. ${ }^{3}$

\section{Table 1. Ten-Item Personality Inventory (TIPI): original version}

Here are a number of personality traits that may or may not apply to you. Please write a number next to each statement to indicate the extent to which you agree or disagree with that statement. You should rate the extent to which the pair of traits applies to you, even if one characteristic applies more strongly than the other.

\begin{tabular}{ccccccc}
$\begin{array}{l}\text { Disagree } \\
\text { strongly }\end{array}$ & $\begin{array}{c}\text { Disagree } \\
\text { moderately }\end{array}$ & $\begin{array}{c}\text { Disagree } \\
\text { a little }\end{array}$ & $\begin{array}{c}\text { Neither agree } \\
\text { nor disagree }\end{array}$ & $\begin{array}{c}\text { Agree } \\
\text { a little }\end{array}$ & $\begin{array}{c}\text { Agree } \\
\text { moderately }\end{array}$ & $\begin{array}{c}\text { Agree } \\
\text { strongly }\end{array}$ \\
\hline 1 & 2 & 3 & 4 & 5 & 6 & 7
\end{tabular}

I see myself as:

1. Extraverted, enthusiastic.

2. Critical, quarrelsome.

3. Dependable, self-disciplined.

4. - Anxious, easily upset.

5. Open to new experiences, complex.

6. Reserved, quiet.

7. Sympathetic, warm.

8. Disorganized, careless.

9. Calm, emotionally stable.

10. Conventional, uncreative.

Note: TIPI scale scoring ( $R$ refers to reverse-scored items): Extraversion: 1, 6R; Agreeableness: 2R, 7; Conscientiousness; 3, 8R; Emotional stability: 4R, 9; Openness to experiences: 5, $10 \mathrm{R}$.

Source: Gosling SD, Rentfrow PJ, Swann WB. Ten item personality measure (TIPI). 2003. At: www.midss.org/content/ ten-item-personality-measure-tipi. Accessed 23 March 2018. 
The TIPI has been used in health professions education to research burnout, stress, and job performance. ${ }^{14}$ There is also evidence that supports use of the TIPI domains in predicting students' academic and clinical performance. Conscientiousness, for example, has been identified as a strong predictor of academic performance as well as clinical learning outcomes among dental and medical students. ${ }^{3,11,19}$ Conscientiousness was found to have positive relationships with professionalism in a sample of medical students in the UK. ${ }^{20}$ Conscientious individuals perform well in jobs, set high goals, and put in extra effort. ${ }^{11,21}$ Conscientiousness had a strong negative relationship to the number of expressions of concern, an indicator of lack of professionalism in students. ${ }^{20}$ Conscientiousness is significant because conscientious individuals show persistence and are motivated to do well even in the face of adversity. ${ }^{10}$

While Conscientiousness is tied to "getting ahead," Openness and Extraversion have been described as "getting along" (with patients). ${ }^{10}$ The trait of Openness facilitates acceptance of a challenging or changing environment, and a person who is open is likely to have good problem-solving skills. Smithers and Cunningham found that Openness predicted academic performance in years 2 and 3 at two Canadian dental schools, but students who were less open performed better possibly because of a restrictive curriculum. ${ }^{21}$ Those researchers also found large gains in predictive validity for Extraversion and Openness for predicting academic performance and that those traits gained in significance in later years of the program as applied practice became relevant. Traits such as Extraversion and Openness are related to sociability, which impacts performance in applied settings. ${ }^{19}$ Extraversion is linked to professions in which there is physician-patient interaction, ${ }^{11}$ and one study found that medical students scored higher on Extraversion and Openness than students in the humanities. ${ }^{22}$ Low scores on neuroticism (or high scores on emotional stability) were associated with better performance in the clinics. ${ }^{3}$ In a study that compared medical students and police officer recruits, the factors of conscientiousness, neuroticism, and openness accurately classified individuals into the two groups, with medical students scoring higher on neuroticism and openness but lower on conscientiousness. ${ }^{23}$ However, Agreeableness is somewhat problematic with lower reliability than the other scales. ${ }^{3,15}$

There is little evidence in dental education about the role of non-cognitive traits in professionalism. In a Canadian dental school sample, although
Agreeableness was found to have a significant relationship to clinical education, Openness had a significant negative relationship contrary to expectations, suggesting the need for more research on this construct in dental education. ${ }^{21}$ Two other studies found the trait of Agreeableness correlated with dental students' academic and clinical performance., ${ }^{3,19}$ However, there is a need for a standardized scale that can be used across dental education to measure dental students' professionalism. The aim of this study was thus to establish a scale to assess dental students' professionalism by adding to the TIPI's five dimensions a set of descriptors that define professional behavior in dental students. The resulting Patient Management and Professionalism Scale (PMPS) was then tested with a cohort of graduating students at the University of Michigan School of Dentistry.

\section{Methods}

The study was determined to be "not regulated" (HUM00129063) by the University of Michigan Institutional Review Board. One clinic director and one patient care coordinator from each of the four clinics at the University of Michigan School of Dentistry participated in constructing the PMPS and served as experts (total of eight experts).

Students are assigned to one of the four vertically integrated clinics at the school. Clinic directors are clinical faculty members at the school, while patient care coordinators are administrative personnel who work in each of the clinics with the clinic directors. Patient care coordinators monitor students' progress through data management of their clinical performance with respect to how they manage patient treatment and needs; the coordinators also advise students on patient care and personal issues that impact clinical performance. Patient care coordinators act as a liaison among faculty, students, and patients and work closely with students in their patient treatment activity. They monitor students' professionalism, number and frequency of appointments, progress in treatment planning, and case completions on a daily basis and assign a patient management grade for each student based on these dimensions. The total years of experience in the position for this group of experts was 165 years with an average of 21 years per person and a range of 9 to 29 years.

Each expert provided a description for each trait in the TIPI in the context of student behaviors in the clinics. These descriptions were combined to 
create a single scale (Table 2). After the raters familiarized themselves with all the descriptions, they then rated members of the DDS graduating class of 2017 $(n=95)$ who were part of their clinic on each of the five dimensions (and ten traits). A Qualtrics survey was used for rating each trait on a seven-point scale: $1=$ strongly disagree, $2=$ disagree moderately, $3=$ disagree a little, $4=$ neither agree nor disagree, $5=$ agree a little, $6=$ agree moderately, and $7=$ agree strongly. A picture of each student was provided in the Qualtrics survey. While the experts completed their ratings, descriptions of each trait were given in paper form to each rater to aid the rating, and a description was also posted on a projector screen. International dentists were excluded from this sample as their experiences were different from students who were not international dentists, both in prior experiences and experiences with the curriculum.

\section{Results}

Scores for each student were calculated by taking the average of scores for the two raters for each of the two subscales for each of the five dimensions. Mean scores on the five dimensions for the PMPS ranged from $4.92(\mathrm{SD}=1.41)$ for Extraversion to 5.35 $(\mathrm{SD}=1.28)$ for Agreeableness on the seven-point scale (Table 3). There was a significant difference in Conscientiousness when scores on the five dimensions were compared for the two dominant ethnic groups: the mean score for whites was $5.38(\mathrm{SD}=1.59)$ and for Asians it was $4.01(\mathrm{SD}=1.84)$. There were no differences between males and females on any of the five dimensions although females scored higher on all of the dimensions.

The reliability (Cronbach's alpha) for the PMPS subscales measuring the five dimensions ranged from 0.78 (Agreeableness) to 0.92 (Conscientiousness) (Table 4). Correlations between rater one (the clinic directors) and rater two (the patient care coordinators) ranged from 0.40 (Agreeableness) to 0.76 (Conscientiousness) and were all positive and significant. Thus, Conscientiousness had the highest reliability scores and Agreeableness the lowest.

For validity, three of the five dimensions on the PMPS were significantly and positively correlated, while Agreeableness and Extraversion were not (Table 5). All but one of the five dimensions (Agreeableness) had significant positive correlations with both patient management grade and cumulative GPA at the end of the program. Patient management

\section{Table 2. The Patient Management and Professionalism Scale: domains and descriptions}

\begin{tabular}{|c|c|}
\hline Domain/Items & Description \\
\hline \multicolumn{2}{|l|}{ Extraversion } \\
\hline $\begin{array}{l}\text { Extraverted, } \\
\text { enthusiastic } \\
\text { (1) }\end{array}$ & $\begin{array}{l}\text { Exudes self-confidence; not shy when talking to instructors. } \\
\text { Outgoing, able to relate to the patient; organized, eager to learn, asks good questions, wants to get better. } \\
\text { Appears to "know their stuff," have their act together. } \\
\text { Offers to treat patients who present to the school without an appointment. } \\
\text { Looks for other clinical work if a patient cancels. } \\
\text { Makes the patient comfortable. } \\
\text { Positive approach/attitude towards patients, even difficult ones. }\end{array}$ \\
\hline $\begin{array}{l}\text { Reserved, } \\
\text { quiet } \\
(6, R)\end{array}$ & $\begin{array}{l}\text { May not ask for help even when needed. } \\
\text { Shy, unassertive, not confident; may have a hard time relating to patients. } \\
\text { Does not present a problem until it becomes a major issue. } \\
\text { Responses are always measured. }\end{array}$ \\
\hline \multicolumn{2}{|l|}{ Agreeableness } \\
\hline $\begin{array}{l}\text { Critical, } \\
\text { quarrelsome } \\
(2, \mathrm{R})\end{array}$ & $\begin{array}{l}\text { Defensive/not receptive when given critical feedback by faculty/staff. } \\
\text { Argues about management grade. } \\
\text { Questions instructor's knowledge/abilities. } \\
\text { Always makes excuse why a rule shouldn't apply to them. }\end{array}$ \\
\hline $\begin{array}{l}\text { Sympathetic, } \\
\text { warm } \\
(7)\end{array}$ & $\begin{array}{l}\text { Sincerely shows care and concern for those less fortunate. } \\
\text { Willing to take on patients who are difficult behaviorally. } \\
\text { Caring, interested in the patient as a person; shows empathy/kindness for the patient. } \\
\text { Able to work with patients who have a dental phobia. } \\
\text { Listens to and engages patients. } \\
\text { Understanding when things don't go as planned. }\end{array}$ \\
\hline
\end{tabular}




\section{Table 2. The Patient Management and Professionalism Scale: domains and descriptions (continued)}

\begin{tabular}{|c|c|}
\hline Domain/Items & Description \\
\hline \multicolumn{2}{|l|}{ Conscientiousness } \\
\hline $\begin{array}{l}\text { Dependable, } \\
\text { self-disciplined } \\
\text { (3) }\end{array}$ & $\begin{array}{l}\text { Most likely to do test cases early and actually have read the criteria. } \\
\text { Comes to see a patient care coordinator to clear off their overdue report (without asking). } \\
\text { Is prepared for procedures that require some prep ahead of appointment (did their homework prior } \\
\text { to presenting). } \\
\text { Schedules patient family on a timely basis. } \\
\text { Is confident in the treatment setting. } \\
\text { Always in clinic; starts and finishes on time. } \\
\text { Turns reports in on time. } \\
\text { Doesn't have to be told something twice when asked to do something. } \\
\text { Does not lie or cheat. }\end{array}$ \\
\hline $\begin{array}{l}\text { Disorganized, } \\
\text { careless } \\
(8, R)\end{array}$ & $\begin{array}{l}\text { Lack of focus; appears scatter-brained. } \\
\text { Misses deadlines for turning things in for assignments such as test cases. } \\
\text { Not prepared for clinic; asks questions that he/she should know. } \\
\text { Not prepared for the planned procedure. } \\
\text { Leaves the cubicle dirty/disorderly even when many materials and equipment are needed for the procedure. } \\
\text { Too many overdue patients on the student's list consistently. } \\
\text { Disposes of sheets with patient information in the garbage instead of shredding. }\end{array}$ \\
\hline \multicolumn{2}{|l|}{ Emotional stability } \\
\hline $\begin{array}{l}\text { Anxious, easily } \\
\text { upset } \\
(4, R)\end{array}$ & $\begin{array}{l}\text { Lacks confidence, seeks help too frequently; patients ask for a new provider because student doesn't } \\
\text { show confidence; wants to be shown how to do procedures. } \\
\text { Nervous; self-critical; edgy; smallest difficulty throws them off. } \\
\text { Overconfident in abilities, then are let down when a less than acceptable result occurs. } \\
\text { May cry when the unexpected happens. }\end{array}$ \\
\hline $\begin{array}{l}\text { Calm, } \\
\text { emotionally } \\
\text { stable } \\
\text { (9) }\end{array}$ & $\begin{array}{l}\text { In control, hard to upset, does not get easily flustered; never panics regardless of what happens; confident. } \\
\text { Interacts well with patients, staff, and faculty. } \\
\text { Accepts and learns from criticism. } \\
\text { Handles situations well when things don't go as planned. }\end{array}$ \\
\hline
\end{tabular}

Openness to experiences

Open to new Willing to accept a patient to treat who has a challenging personality.

experiences, $\quad$ Excited about learning new techniques; likes to learn/seeks new/different ways of doing things.

complex $\quad$ Expresses own ideas to see if they might work.

(5)

Thinks outside the box.

Conventional, Doesn't think outside the box; not receptive to new ideas.

uncreative Has difficulty making decisions when they are outside the norm.

$(10, R) \quad$ Rigid, goes by the book when some flexibility is possible; has one proven process and sticks with it.

Continuously needs to ask for directions.

Note: In Item column, numbers indicate the order in which this trait is presented on the actual scale. $\mathrm{R}$ indicates that the item is reverse-coded.

grade is a score that measures aspects of students' professional behavior in the clinic such as adherence to HIPAA, documenting cancelled patient appointments, communicating tactfully and truthfully, and being respectful. This score is assigned by the patient care coordinators who monitor the student's behavior. For this study, letter grades were converted to a five-point scale.

Several criteria were used to ensure adequate interpretation of the factor structure. ${ }^{24,25}$ An Exploratory Factor Analysis using the Principal Component Analysis with Eigenvalues $>1.5$ showed strong factor loadings on a single factor called "Professionalism" (Table 6). This finding was also confirmed by the scree plot. Factor loadings ranging from 0.58 (Extraversion) to 0.95 (Openness to Experiences) with these five factors explaining $66 \%$ of variance ensured that the factor structure had high interpretability. The KMO's test confirmed that the sampling was adequate to run the factor analysis, and the significant Bartlett's test of sphericity confirmed that factor analysis was suitable for these data. The values for skewness were less than 2 , and kurtosis was less than 7 as recommended values of normality. 


\begin{tabular}{|c|c|c|c|c|c|}
\hline Variable & Agreeableness & Emotional Stability & Conscientiousness & Openness to Experiences & Extraversion \\
\hline \multicolumn{6}{|l|}{ Race/Ethnicity } \\
\hline White $(n=67-68)$ & $5.36(1.23)$ & $5.24(1.38)$ & $5.38(1.59)$ & $5.11(1.14)$ & $5.00(1.27)$ \\
\hline Asian $(n=19-21)$ & $5.37(1.24)$ & $5.00(1.55)$ & $4.01(1.84)$ & $4.46(1.62)$ & $4.73(1.72)$ \\
\hline t value (sig) & $0.04(p>0.05)$ & $0.66(p>0.05)$ & $3.32(p<0.05)^{*}$ & $2.03(p>0.05)$ & $0.78(p>0.05)$ \\
\hline \multicolumn{6}{|l|}{ Gender } \\
\hline Female $(n=33)$ & $5.56(1.14)$ & $5.30(1.38)$ & $5.45(1.59)$ & $5.08(1.38)$ & $5.03(1.50)$ \\
\hline Male $(n=59-61)$ & $5.22(1.35)$ & $5.15(1.43)$ & $4.86(1.79)$ & $4.85(1.29)$ & $4.86(1.38)$ \\
\hline t value (sig) & $1.21(p>0.05)$ & $0.49(p>0.05)$ & $1.59(p>0.05)$ & $0.80(p>0.05)$ & $0.57(p>0.05)$ \\
\hline Overall & $5.35(1.28)$ & $5.21(1.40)$ & $5.08(1.73)$ & $4.95(1.32)$ & $4.92(1.41)$ \\
\hline
\end{tabular}

Note: Scores were on seven-point scale from $1=$ strongly disagree to $7=$ strongly agree.

$* \mathrm{p}<0.05$

Table 4. Correlation between rater 1 and rater 2 and reliability of each Patient Management and Professionalism Scale subscale

\begin{tabular}{lcc} 
Dimension & Correlation & $\begin{array}{c}\text { Reliability } \\
\text { of Subscale }\end{array}$ \\
\hline Agreeableness & $0.40^{*}$ & 0.78 \\
Emotional stability & $0.59^{*}$ & 0.88 \\
Conscientiousness & $0.76^{*}$ & 0.92 \\
Openness to experiences & $0.66^{*}$ & 0.88 \\
Extraversion & $0.57^{*}$ & 0.80 \\
${ }^{*} \mathrm{p}<0.01$ & & \\
\hline
\end{tabular}

\section{Discussion}

These results suggest that the PMPS is a viable way to measure professionalism in dental students. It is based on a sound personality framework, and its adaptation to dental education was based on observations of actual student behaviors in an applied clinical setting in the context of patient care. This scale does not aim to capture all aspects of professionalism. However, it does offer a way to look at professionalism in dental education for which good measures are lacking. The qualitative approach of this scale is

Table 5. Correlations among students' scores on five dimensions of the Patient Management and Professionalism Scale, patient management grade, and cumulative GPA

\begin{tabular}{|c|c|c|c|c|c|c|}
\hline Dimension/Grade & Extraversion & Conscientiousness & $\begin{array}{l}\text { Emotional } \\
\text { Stability }\end{array}$ & $\begin{array}{l}\text { Openness to } \\
\text { Experiences }\end{array}$ & $\begin{array}{c}\text { Patient Management } \\
\text { Grade }\end{array}$ & $\begin{array}{c}\text { Cumulative } \\
\text { GPA }\end{array}$ \\
\hline Agreeableness & 0.11 & $0.53^{* *}$ & $0.63^{* *}$ & $0.63^{* *}$ & 0.20 & 0.12 \\
\hline \multicolumn{2}{|l|}{ Extraversion } & $0.43^{* *}$ & $0.40^{* *}$ & $0.62 * *$ & $0.21 *$ & $0.32 * *$ \\
\hline \multicolumn{2}{|l|}{ Conscientiousness } & & $0.64 * *$ & $0.78^{* *}$ & $0.48^{* *}$ & $0.53^{* *}$ \\
\hline \multicolumn{2}{|l|}{ Emotional stability } & & & $0.80^{* *}$ & $0.23 *$ & $0.35^{* *}$ \\
\hline \multicolumn{2}{|c|}{ Openness to experiences } & & & & $0.26^{*}$ & $0.45^{* *}$ \\
\hline \multicolumn{2}{|c|}{ Patient management grade } & & & & & $0.41^{* *}$ \\
\hline${ }^{*} \mathrm{p}<0.05, * * \mathrm{p}<0.01$ & & & & & & \\
\hline
\end{tabular}

Table 6. Factor loadings, skewness, and kurtosis for five dimensions of the Patient Management and Professionalism Scale

\begin{tabular}{lcccc} 
Dimension & Factor Loadings & Number of Items & Skewness & Kurtosis \\
\hline Extraversion & 0.58 & 2 & -0.65 & -0.19 \\
Agreeableness & 0.76 & 2 & -0.65 & -0.44 \\
Conscientiousness & 0.86 & 2 & -0.68 & -0.91 \\
Emotional stability & 0.87 & 2 & -0.87 & 0.20 \\
Openness to experiences & 0.95 & 2 & -0.56 & -0.18
\end{tabular}

Note: Total variance explained: $66 \%$; KMO test of sampling adequacy: 0.77; and Bartlett's Test of Sphericity: $p=0.00$. 
useful in that it can be used by multiple raters, and it has the flexibility to be adapted to different settings. In a systematic review of professionalism instruments, the three best instruments came from nursing and psychology, not dentistry. ${ }^{3}$ The PMPS would be even more valuable if used with other measures of professionalism.

Students scored from 4.92 to 5.36 (on a scale of 1 to 7) across the five dimensions, indicating fairly high scores on the dimensions. Similar mean scores were obtained in a study using the original form of TIPI in a sample of over 900 U.S. undergraduate students $^{15}$ (4.83 to 5.41) and in the normative data provided by Gosling et al. (4.44 to 5.40). ${ }^{17}$ Whites and Asians were the two dominant groups in our sample, comprising $94 \%$ of the sample. The significantly higher score for Conscientiousness for whites as compared to Asians may be related to a power issue as the sample for Asians was small $(\mathrm{n}=21)$ and a more adequate sample is needed to verify this finding. The lower scores for the Asian students could also indicate a rater bias and a cultural bias, given that the construct of professionalism may be influenced by Anglo-Saxon perspectives and be biased against other ethnic groups. ${ }^{6}$ Similarly, the trend for females to score higher on all dimensions may well result in significance in a larger sample. The reliabilities of the scales (Cronbach's alpha) were all high $(0.78$ to 0.90 ), and correlations between raters were all positive and significant. Conscientiousness had the highest scale reliability as well as the highest correlation between raters, indicating that this subscale was performing well.

The five dimensions were positively and significantly correlated with each other with the exception of Agreeableness and Extraversion. Agreeableness was the only dimension that had no correlation with the patient management grade and cumulative GPA. Agreeableness also had the lowest correlation between raters and the lowest scale reliability. The data on Agreeableness showed that it may be a problematic construct, as suggested in another study. ${ }^{15}$ The factor analysis indicated that Agreeableness was a conceptual part of a group of attributes that measured professionalism given its reasonably high loading on this factor. However, in this study, the facet of Agreeableness did not predict patient management behavior or cumulative GPA unlike the other four dimensions. Further research with other validating measures of professionalism is needed to evaluate the lack of the association with Agreeableness and to confirm that, as a single facet, it is not a useful measure of professionalism.
Exploratory Factor Analysis showed factor loadings on a single factor called "Professionalism." The presence of a single factor confirmed that the scales were all measuring one construct and therefore underscored that the scale is a solid, coherent measure of professionalism. This study suggests that Openness, with a loading of 0.95 , may be a significant way to define professionalism. The experts defined Openness as thinking outside the box, being open to new learning, expressing new ideas, and being willing to take on difficult patients. All these characteristics are critical behaviors in a rapidly changing health care world with increasingly diverse patients and constant change in treatment planning. The high factor loadings $(0.58$ to 0.95$)$ and the total variance explained $(66 \%)$ suggest that this scale has good construct validity.

The PMPS is of value because it provides a qualitative description of professionalism that is derived from actual observations in applied settings while at the same time allowing for a quantitative score. The eight experts used their many years of experience to provide qualitative descriptors of students' ideal behaviors in the clinic. There was remarkable agreement in the experts' initial descriptions of the five dimensions, which made it possible to combine them into a single scale. The PMPS has the capacity to be used longitudinally as well as by multiple raters. All these qualities make it a potentially good measure of professionalism. ${ }^{4}$ The PMPS can be used at other dental schools while at the same time allowing for other descriptors to be added by those institutions. The qualitative nature of the scale allows flexibility for other schools to add their own criteria. It can be used early in the curriculum and therefore offers remediation opportunities that can be implemented in the form of monitoring. ${ }^{2}$

The five dimensions of the PMPS can also help provide a profile of the ideal dental student. Such a student is confident, has a positive attitude, and relates well to patients (Extraversion); is caring, listens to patients, and is willing to take on patients with behavioral problems (Agreeableness); is timely, truthful, and prepared for procedures (Conscientiousness); is in control of emotions, accepts and learns from criticism, and handles unplanned situations well (Emotional Stability); and is willing to accept patients with a challenging personality, is excited about new ideas, and can think outside the box (Openness). Overall, this student is confident, timely, and truthful; handles difficult situations with patients with equanimity; and is open to new ideas and learning 
from criticism as well as open to treating all kinds of patients. In contrast, the not-so-ideal dental student is shy and does not ask for help (reserved, quiet); is defensive when faced with critical feedback and argues about grades (critical, quarrelsome); is not focused, not prepared, and does not manage patients well (disorganized, careless); is nervous or overconfident (anxious, easily upset); and is not receptive to new ideas, is rigid, and has difficulty making decisions (conventional, uncreative). Overall, this not-so-ideal student is defensive, argumentative, disorganized, and rigid and does not manage patients well. It is highly plausible that this type of student would be responsive to constructive feedback, so identifying these behaviors early in the program would be useful.

One limitation of this study is that it represents data from a single cohort of students, so future replication with other samples at other sites is needed for further validation of the scale. It would also be useful to validate this scale with other, more diverse sets of professional measures. Suggestions for future research using this scale and for the assessment of professionalism in general emerge from recommendations by an international working group that evaluated professionalism in medical education. ${ }^{6}$ The PMPS offers an opportunity to compare definitions of professionalism with other health care professions. In the future, the PMPS can be used to assess the relationship between professionalism and quality of patient care. Data from this scale can be used to change the culture of education and practice-in particular, the hidden curriculum. For enhancement of professionalism, a positive learning environment enforcing elements of modelling and collaborative learning in applied context is critical. ${ }^{9}$ In fact, at our institution, we are considering changing grades from a letter grade system to a pass/fail system to facilitate more mastery learning and professional behaviors. Ideally, since professionalism must be demonstrated in all clinical competencies and cannot be assessed by a single instrument, the scores for the PMPS need to be part of a systematic array of instruments. ${ }^{12}$

\section{Conclusion}

This study suggests that the PMPS is a useful adaptation of the TIPI and a psychometrically sound measure to assess professionalism in dental students. The value of using the TIPI instrument as a basis is that it is based on a universal framework to examine personality to measure non-cognitive traits. The PMPS demonstrated very good reliability and validity in this study. The subscale reliabilities were very satisfactory, and the PMPS had a positive significant correlation with academic performance (cumulative GPA) and professional behaviors tied to patient management (patient management grades) at the end of the DDS program. The subscale of Agreeableness did not have significant relationships with grades or patient management behavior, so its importance needs to be evaluated in future studies. The PMPS can help with better assessment of noncognitive skills needed for a dynamic and diverse oral health care environment as it is brief, adaptable, and easy to use by multiple raters.

\section{Acknowledgments}

I would like to thank the following for serving as experts: Ron and Don Heys, Henry Temple, Mark Snyder, Clarissa Lusk, Mary Garrelts, Cheryl Quiney, and Ann Somppi. I would like to thank the following for their administrative support: Patricia Katcher and Rachel Daniels. I would like to thank Katherine Shin for her edits of the initial manuscript.

\section{REFERENCES}

1. Virtue SM, Tellez M. Identifying noncognitive skills that contribute to dental students' success: dental faculty perspectives. J Dent Educ 2017;81(3):300-9.

2. Boon KTJ. Ethical and professional conduct of medical students: review of current assessment measures and controversies. J Med Ethics 2004;30:221-6.

3. Chamberlain TC, Cunningham DP. Personality as a predictor of professional behavior in dental school: comparisons with dental practitioners. J Dent Educ 2005;69(11): 1222-37.

4. Lynch DSP, Eiser A. Assessing professionalism: a review of the literature. Med Teach 2004;26:366-73.

5. Mann KV, Millar N, Andreou P. Achievement of noncognitive goals of undergraduate medical education: perceptions of medical students, residents, faculty, and other health professionals. Med Educ 2005;39(1):40-8.

6. Hodges BD, Ginsburg S, Cruess R, et al. Assessment of professionalism: recommendations from the Ottawa 2010 conference. Med Teach 2011;33(5):354-63.

7. Li H, Ding N, Zhang Y, et al. Assessing medical professionalism: a systematic review of instruments and their measurement properties. PLoS One 2017;12(5):e0177321.

8. Van De Camp K, Grol R, Bottema B. How to conceptualize professionalism: a qualitative study. Med Teach 2004;26:696-702.

9. Taylor C, Grey N, Checkland K. Professionalism: it depends where you're standing. Br Dent J 2017;222(11): 889-92.

10. Lievens F, Ones DS, Dilchert S. Personality scale validities increase throughout medical school. J Appl Psychol 2009;94(6):1514-35. 
11. Hojat M. Personality assessments and outcomes in medical education and the practice of medicine: AMEE guide no. 79. Med Teach 2013;35(7):e1267-301.

12. Farah-Franco S, Deoghare H. Advancing measurement of dental students' professionalism. J Dent Educ 2017;81(11):1338-44.

13. Heller D, Komar S, Lee WB. The dynamics of personality states, goals, and well-being. Pers Soc Psychol Bull 2007;33:898-910.

14. Ahmed AJB. Critical synthesis package: ten-item personality inventory (TIPI) - a quick scan of personality structure. MedEdPORTAL 2013;9.

15. Ehrhart MG, Roesch SC. Testing the latent factor structure and construct validity of the ten-item personality inventory. Pers Indiv Diff 2009;47(8):900-5.

16. Mccrae RCP. Personality trait structure as a human universal. Am Psychol 1997;52:509-16.

17. Gosling SD, Rentfrow PJ, Swann WB. Ten item personality measure (TIPI). 2013. At: www.midss.org/content/ ten-item-personality-measure-tipi. Accessed 23 March 2018.

18. Gosling SD, Rentfrow PJ, Swann WB Jr. A very brief measure of the big-five personality domains. J Res Pers 2003;37:504-28.
19. Doherty EN. Personality factors and medical training: a review of literature. Med Educ 2011;45(2):132-40.

20. McLachlan J. The conscientiousness index: a novel tool to explore students' professionalism. Acad Med 2009; 84:559-65.

21. Smithers S, Cunningham DP. What predicts performance in Canadian dental schools? J Dent Educ 2004;68(5): 598-613.

22. Lievens F, De Fruyt F, De Maeseneer J. Medical students' personality, characteristics, and academic performance: a fiver-factor model perspective. Med Educ 2002;36: 1050-6.

23. Chibnall JT, Detrick P. Are medical students agreeable? An exploration of personality in relation to clinical skills training. Med Teach 2009;31:e311-5.

24. Schonrock-Adema J, Heijne-Penninga M, Van Hell EA, Cohen-Schotanus J. Necessary steps in factor analysis: enhancing validation studies of educational instrumentsthe PHEEM applied to clerks as an example. Med Teach 2009;31(6):e226-32.

25. Kossioni AE, Lyrakos G, Ntinalexi I, et al. The development and validation of a questionnaire to measure the clinical learning environment for undergraduate dental students (DECLEI). Eur J Dent Educ 2014;18(2):71-9. 